\title{
Harmonic Analysis for a 6-pulse Rectifier
}

\author{
Sudeep Pyakuryal and Mohammad Matin \\ Department of Electrical and Computer Engineering University of Denver
}

\begin{abstract}
When sinusoidal voltage is converted into dc voltage in medium-voltage high-power applications, the switching devices used in the rectifier circuit inject harmonic component to the utility grid. The harmonic component causes various problems in the power system. IEEE std 519-1992 limits the amount of harmonics that is acceptable in the power system so that the undesirable effects of harmonic distortion are minimized.

Among various harmonic distortion mitigation techniques, the pulse multiplication technique is investigated in this paper. A 6-pulse rectifier is modeled in Alternative Transients Program (ATP). Voltage and Current waveforms are obtained and the amounted of harmonic distortion is calculated. 6-pulse rectifier is a building block for higher order rectifier like 12-pulse, 18-pulse, 24-pulse rectifiers.

Results suggest that the total harmonic distortion, THD, produced by an ideal 6-pulse rectifier is higher than the IEEE limit and therefore higher order pulse rectifier must be used to control the THD.
\end{abstract}

Keywords: AC to DC converter, Rectifier, THD, Thyristor, ATP

\section{INTRODUCTION}

Medium-voltage high-power drives are widely use in the industry. They are used in the petrochemical industry for pipeline pumps, in the cement industry for fans, in water pumping station for pumps, in transportation industry for traction applications, mills in the metal industry for steel rolling and in many other industries for various applications [1]-[8].

These drives are made up of power electronic components like power diodes, power IGBT, power thyristor etc. When these devices are turned on and off at certain frequency, these devices produce nonsinusoidal components called harmonics. These devices act as non-linear load to the utility [9].

IEEE standard 519-1992 requires that the amount of harmonic distortion produced by these drives should be under specified value. Criteria dictate that any individual harmonics should not be more than $3 \%$ and total harmonic distortion (THD) should not be more than 5\% [10].

Presence of harmonics in power system can give rise to a variety of problems including equipment overheating, reduced power factor, deteriorating performance of electrical equipment, the incorrect operation of protective relays, interference with communication devices, and in some cases, circuit resonance to cause electric apparatus dielectric failure and other type of severe damage [11].

In order to meet the harmonic requirement set by IEEE standard 519-1992, major high-power drive manufactures around the world are increasingly using multi-pulse rectifier in their drive at front end converter. The rectifiers can be configured as 12-, 18-, and 24-pulse rectifiers powered by a transformer with a number of secondary windings. Each secondary winding feeds a 6-pulse rectifier. To achieve 12-pulse rectifier two 6-pulse rectifiers are used in parallel. Likewise, for 18-pulse, three 6-pulse rectifiers, and for 24-pulse, four 6-pulse rectifiers are connected in parallel [12]-[15].

The main feature of the multi-pulse rectifier is its ability to reduce the line harmonic distortion. This is achieved by the phase-shifting transformer through which some of the lower order harmonic currents generated by the six-pulse rectifiers are cancelled. In general, higher the number of rectifier pulses, the lower the line current distortion [12]-[15].

Multi pulse rectifier eliminates the need of using any LC filter or power factor compensators which leads to the elimination of possible LC resonance. The use of phase shifting transformer provides an effective means to block common-mode voltages generated by the rectifier which would otherwise appear on electric motor terminals leading to premature failure of winding insulation [16]

The multi-pulse rectifier can be built using diodes or thyristors as switching device. In case of diodes, dc output voltage cannot be controlled. On the other hand, thyristor provides the ability to control the dc output voltage. Fig 1 shows a general block diagram of medium-voltage drive [17] 


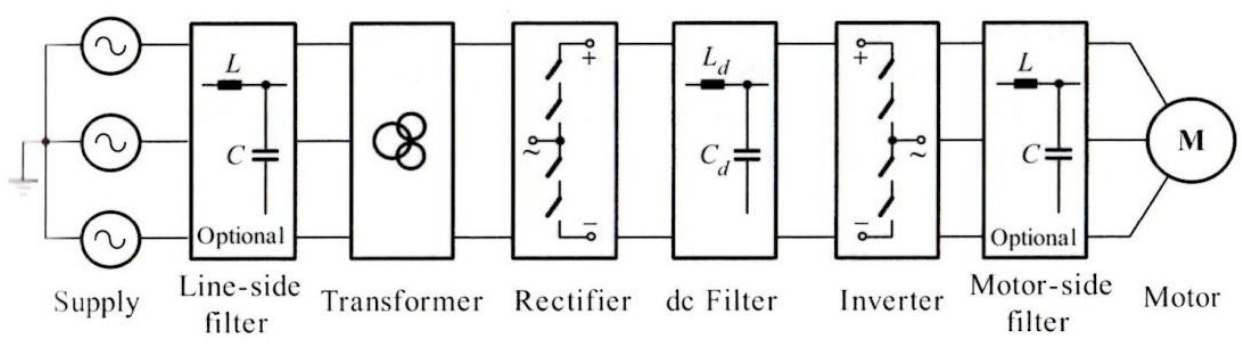

Figure 1. General block diagram of the MV drive

\section{IDEAL SIX-PULSE RECTIFIER}

Fig 2 shows a simplified circuit diagram of a six-pulse thyristor rectifier. The inductance $L_{s}$ is the total inductance including the line inductance, transformer reactance, and line reactor between the utility and the rectifier. For the ideal rectifier $\mathrm{L}_{\mathrm{s}}$ is assumed to be zero. On the dc side a choke $\mathrm{L}_{\mathrm{d}}$ is used to make the dc current ripple free [18]. The RC snubber circuits for thyristor are not shown in Fig 2 but are considered in the computer model created in alternative transients program (ATP) [19].

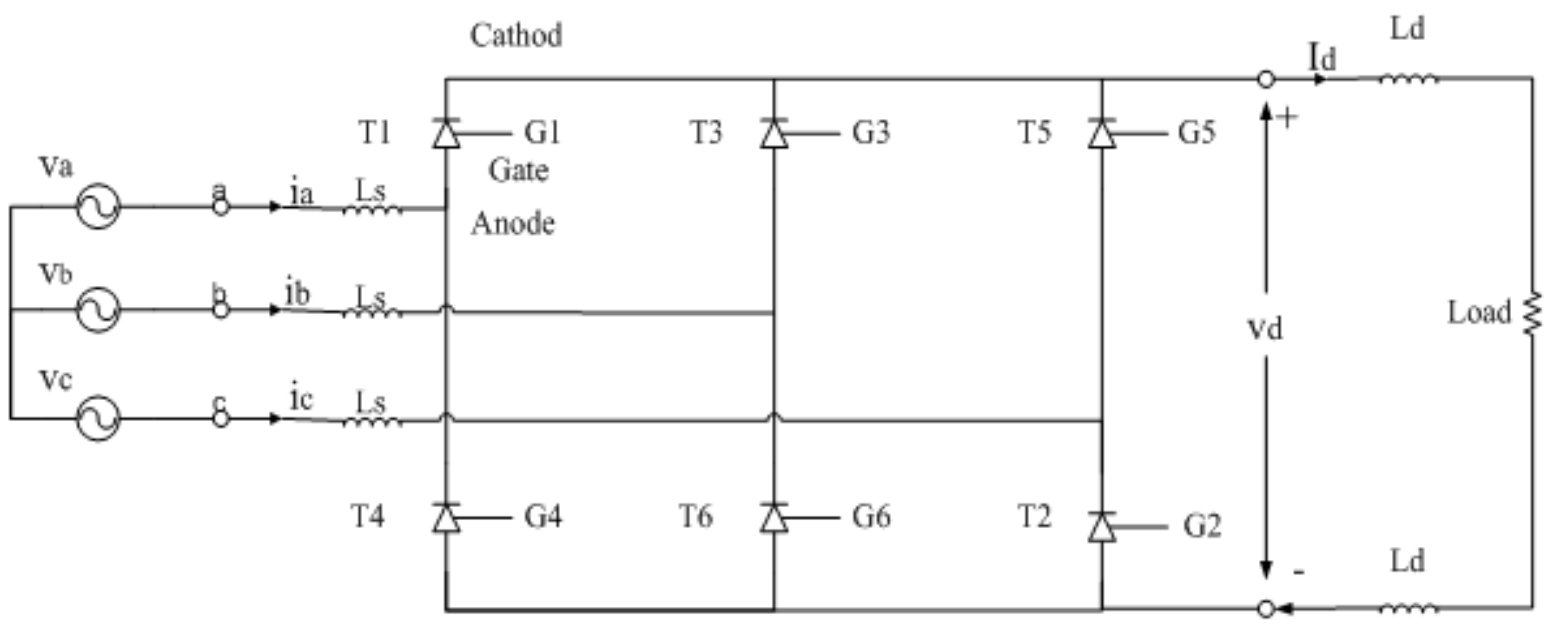

Figure 2. Simplified circuit diagram of a six-pulse thyristor rectifier

Fig 3 shows typical waveforms of the rectifier, where $\mathrm{v}_{\mathrm{a}}, \mathrm{v}_{\mathrm{b}}$, and $\mathrm{v}_{\mathrm{c}}$ are the phase voltages of the utility supply, P1 thru P6 are the gate firing pulses for thyristors T1 thru T6 respectively and $\alpha$ is the firing angle of the thyristors.

During interval I, thyristors T1 and T6 are conduct assuming T6 was conducting prior to turn on of T1. The positive dc voltage is $v_{p}$ with respect to ground is $v_{a}$ and the negative bus voltage $v_{n}$ i.e. equal to $v_{b}$. The $d c$ output voltage can be found from $\mathrm{v}_{\mathrm{d}}=\mathrm{v}_{\mathrm{p}}-\mathrm{v}_{\mathrm{n}}=\mathrm{v}_{\mathrm{ab}}$. The line currents can be given as $\mathrm{i}_{\mathrm{a}}=\mathrm{I}_{\mathrm{d}}, \mathrm{i}_{\mathrm{b}}=-\mathrm{I}_{\mathrm{d}}$, and $\mathrm{i}_{\mathrm{c}}=0$.

During interval II, thyristor T6 is turned off after T2 turns on and the de current $I_{d}$ is commuted from T6 to T2. Thus T1 and T2 are conducting. The positive dc voltage $v_{p}$ is still the same i.e. $v_{p}=v_{a}$ but the negative bus voltage $\mathrm{v}_{\mathrm{n}}$ is equal to $\mathrm{v}_{\mathrm{c}}$. The dc output voltage can be found from $\mathrm{v}_{\mathrm{d}}=\mathrm{v}_{\mathrm{p}}-\mathrm{v}_{\mathrm{n}}=\mathrm{v}_{\mathrm{ac}}$. The line currents can be given as, $i_{\mathrm{a}}=\mathrm{I}_{\mathrm{d}}, \mathrm{i}_{\mathrm{b}}=0$, and $\mathrm{i}_{\mathrm{c}}=-\mathrm{I}_{\mathrm{d}}$.

Following the same procedure all the voltage and current waveforms in other interval can be obtained. It should be noted that the number of thyristor and gate is also the sequence of their firing.

The average dc output voltage can be given as [17]

$\mathrm{V}_{\mathrm{d}}=1.35 \mathrm{~V}_{\mathrm{LL}} \cos \alpha$

The equation (1) depicts that the rectifier dc output voltage $V_{d}$ is positive when the $\alpha$ is less than $\pi / 2$ and becomes negative for an $\alpha$ greater than $\pi / 2$. However, the dc current $I_{d}$ is always positive irrespective of the polarity of the dc output voltage. The technique to control the dc output voltage by firing angle, $\alpha$, is called phase-control technique [20].

When the rectifier produces positive de voltage, the power is delivered from utility to the load. With a negative dc voltage, the rectifier operates as an inverter and the power is fed from the load back to utility. This often takes place during rapid deceleration when the kinetic energy of the rotor and its mechanical load is converted to the electric energy by the converter working in inverter mode and are used for dynamic braking. 


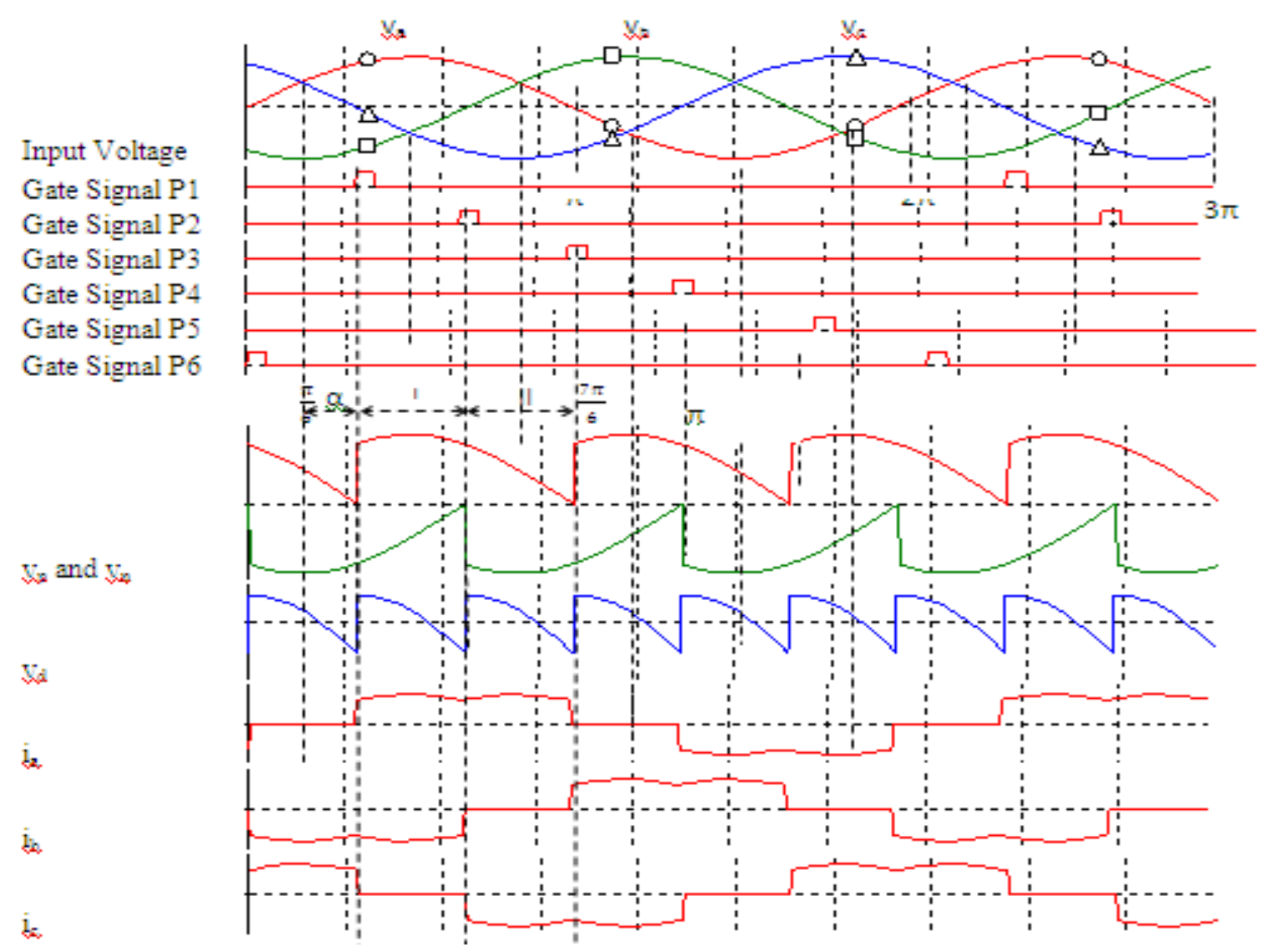

Figure 3 Waveform of an ideal six-pulse thyristor rectifier operating at $\alpha=30^{\circ}$

The line current $i_{a}$ in Fig 3 can be expressed in a Fourier series as [17] $\mathrm{i}_{\mathrm{a}}=\frac{2 \sqrt{3}}{\pi} \mathrm{I}_{\mathrm{d}}\left\{\sin (\omega \mathrm{t}-\varphi)-\frac{1}{5} \sin 5(\omega \mathrm{t}-\varphi)-\frac{1}{7} \sin 7(\omega \mathrm{t}-\varphi)+\frac{1}{11} \sin 11(\omega \mathrm{t}-\varphi)+\frac{1}{13} \sin 13(\omega \mathrm{t}-\varphi)-\frac{1}{17} \sin 17(\omega \mathrm{t}-\varphi)-\frac{1}{19} \sin 19(\omega \mathrm{t}-\right.$ $\varphi)+\ldots \ldots \ldots\}$ $i_{a 1}$. where, $\varphi$ is the phase angle between the supply voltage $\mathrm{v}_{\mathrm{a}}$ and the fundamental frequency line current

The rms value of $i_{a}$ can be given as [17]

$\mathrm{I}_{\mathrm{a}}=\sqrt{ } \frac{2}{3} \mathrm{I}_{\mathrm{d}}=0.816 \mathrm{I}_{\mathrm{d}}$

From which the total harmonic distortion, THD, for the line current $i_{a}$ is [17]

$\mathrm{THD}=\frac{\sqrt{I a^{2}-I a 1^{2}}}{I a 1}=\frac{\sqrt{(0.816 I d)^{2}-(0.78 I d)^{2}}}{0.78 I d}=0.311$

i.e. $\mathrm{THD}=31.1 \%$

where $\mathrm{I}_{\mathrm{a} 1}$ is the rms value of $\mathrm{i}_{\mathrm{a} 1}$.

\section{CONCLUSION AND FUTURE WORK}

The waveform of line currents $i_{a}, i_{b}$, and $i_{c}$ are not sinusoidal as shown in Fig 3 . If these waveforms were perfectly sinusoidal, the total harmonic distortion, THD, would be zero. From equation (4) it can be seen that the THD of an ideal six-pulse thyristor rectifier is $31.1 \%$. This value is significantly higher than the IEEE limit of $5 \%$.

In low-voltage application, THD can also be mitigated using shunt reactor but in a medium-voltage application, using shunt reactor to control the THD is not cost effective, therefore pulse multiplication method is widely used. However, reactance due to cable inductance and transformer inductance will always be there in medium-voltage application and the THD will be mitigated to some extent. But to achieve the THD value under IEEE limit, pulse multiplication must be used.

In future, a practical circuit with cable inductance and transformer inductance will be considered for a 12-pulse and 18-pulse rectifier. To achieve a 12-pulse rectifier, two 6-pulse rectifiers will be connected in 
parallel and to achieve an 18-pulse rectifier, three 6-pulse rectifiers will be connected in parallel. Resultant THD for both the cases will be calculated and waveforms for line currents will be obtained. If neither of these rectifiers produces less than 5\% THD, a 24-pulse rectifier should be investigated.

\section{REFERENCE}

[1] S. Bernert, Recent Development of High Power Converters for Industry and Traction Applications, IEEE Trans on Power Electronics, Vol. 15, No. 6, pp. 1102-1117, 2000

[2] B.P. Schmitt and R. Sommer, Retrofit of Fixed Speed Induction Motors with Medium Voltage Drive Converters Using NPC Three-Level Inverter High-Voltage IGVT Based Topology, IEEE International Symposium on Industrial Electronics, pp. 746-751, 2001

[3] H. Okayama, M. Koyana, et al., Large Capacity High Performance 3-level GTO Inverter System for Steel Main Rolling Mill Drives, IEEE Industry Application Society (IAS) Conference, pp. 174-179, 1996

[4] N. Akagi, Large Static Converters for Industry and Utility Application, IEEE Proceedings, Vol. 89, No. 6, pp. 1750-1755

[5] R. Menz and F. Opprecht, Replacement of a Wound Rotor Motor with an Adjustable Speed Drive for a $1400 \mathrm{~kW}$ Kiln Exhaust Gas Fan, The 44 $4^{\text {th }}$ IEEE IAS Cement Industry Technical Conference, pp. 85-93, 2002

[6] W.C.Rossmann and R.G. Ellis, Retrofit of 22 Pipeline Pumping Stations with 3000-hp Motors and Variable-Frequency Drives, IEEE Trans. On Industry Application, Vol. 34, Issue: 1, pp. 178-186, 1998

[7] N. Zargari and S. Rizzo, Medium Voltage Drives in Industrial Applications, Technical Seminar, IEEE Toronto Section, 37 pages, November 2004

[8] R.A. Hanna and S. Randall, Medium Voltage Adjustable Speed Drive Retrofit of an Existing Eddy Current Clutch Extruder Application, IEEE Trans on Industry Applications, Vol. 33, No. 6, pp. 17501755

[9] S. Bernert, Recent Developments of High Power Converters for Industry and Traction Applications, IEEE Trans on Power Electronics, Vol. 15, No. 6, pp. 1102-1117, 2000

[10] IEEE Std 519-1992

[11] Electromagnetic Transients Analysis Program, ETAP, Manual

[12] M. Ramasubbamma, V. Madhusudan et al, Design Aspect and Analysis for Higher Order Harmonic Mitigation of Power Converter Feeding a Vector Controlled Induction Motor Drives, IEEE-International Conference on Advances in Engineering, Science And Management (ICAESM-2012), pp. 282-287, March 30, 31, 2012

[13] B. Singh, G. Bhuvaneswari et al, Pulse Multiplication in AC-DC Converters for Harmonic Mitigation in Vector Controlled Induction Motor Drives, IEEE Trans on Energy Conversion, Vol. 21, No. 2, pp. 342352,2006

[14] B. Singh, G. Bhuvaneswari et al, Harmonic Mitigation Using 12-pulse AC-DC Converter in VectorControlled Induction Motor Drives, IEEE Trans on Power Delivery, Vol. 21, No. 3, pp. 1483-1492, 2006

[15] S. Pyakuryal and M. Matin, Ripple Control in AC to DC Converter, IOSR Journal of Engineering, under review

[16] S. Wei, N. Zargari et al., Comparison and Mitigation of Common Mode Voltages in Power Converter Topologies, IEEE Industry Application Society (IAS) Conference, pp. 1852-1857, 2004

[17] B. Wu, High-Power Converters and AC Drives. IEEE Press 2006

[18] S. Pyakuryal and M. Matin, Filter Design for AC to DC Converter, IEEE Trans on Power Electronics, under review

[19] ATP Rule Book at www. emtp.org accessed January 2013

[20] S. Pyakuryal and M. Matin, Implementation of AC to DC converter using Thyristor in ATP, IOSR Journal of Engineering, Vol. 2, Issue 11, pp. 6-11, Nov 2012 